\title{
ECG Test Results End Day
}

National Cancer Institute

\section{Source}

National Cancer Institute. ECG Test Results End Day. NCI Thesaurus. Code C119822.

The final day of the electrocardiographic test. 